\title{
Device Tracking and Disposition Supplemental Qualifiers Dataset
}

National Cancer Institute

\section{Source}

National Cancer Institute. Device Tracking and Disposition Supplemental Qualifiers

Dataset. NCI Thesaurus. Code C147204.

A dataset containing supplemental information, specifically non-standard variables, to parent records in the device tracking and disposition domain. 